\title{
Crystallization Pathways and Kinetics of Carbamazepine-Nicotinamide Cocrystals From the Amorphous State by In Situ Thermomicroscopy, Spectroscopy and Calorimetry Studies
}

\author{
K. SEEFELDT, ${ }^{1,2}$ J. MILLER, ${ }^{1}$ F. ALVAREZ-NÚÑ̃EZ, ${ }^{3}$ N. RODRÍGUEZ-HORNEDO ${ }^{1}$ \\ ${ }^{1}$ Department of Pharmaceutical Sciences, 428 Church St. University of Michigan, Ann Arbor, Michigan 48109-1065 \\ ${ }^{2}$ Chemical and Physical Sciences, Schering Plough Research Institute, Summit, New Jersey \\ ${ }^{3}$ Small Molecule Pharmaceutics, Amgen, Thousand Oaks, California
}

Received 30 August 2006; accepted 14 November 2006

Published online in Wiley InterScience (www.interscience.wiley.com). DOI 10.1002/jps.20945

\begin{abstract}
The work presented here was motivated by the premise that the amorphous state serves as a medium to study cocrystal formation. The molecular mobility inherent to amorphous phases can lead to molecular associations between different components such that a single crystalline phase of multiple components or cocrystal is formed. Cocrystallization pathways and kinetics were investigated from amorphous equimolar phases of carbamazepine and nicotinamide using hot-stage polarized microscopy (HSPM), hot-stage Raman microscopy (HSRM), differential scanning calorimetry (DSC), and X-ray powder diffraction (XRPD). Nonisothermal studies revealed that amorphous phases generate cocrystals and that thermal history affects crystallization pathways in significant ways. Two different pathways to cocrystal formation from the amorphous phase were identified: (1) at low heating rates $\left(3^{\circ} \mathrm{C} / \mathrm{min}\right)$ a metastable cocrystalline phase initially nucleates and transforms to the more stable cocrystalline phase of CBZ-NCT, and (2) at higher heating rates $\left(10^{\circ} \mathrm{C} / \mathrm{min}\right)$ individual components crystallize, then melt and the stable cocrystalline phase nucleates and grows from the melt. Isothermal studies above the $T_{\mathrm{g}}$ of the amorphous equimolar phase also confirm the nucleation of a metastable cocrystalline phase from the amorphous state followed by a solid phase mediated transformation to the stable cocrystalline phase. Cocrystallization kinetics were measured by image analysis and by thermal analysis from small samples and are described by the Avrami-Erofeev model. These findings have important implications for the use of amorphous phases in the discovery of cocrystals and to determine the propensity of cocrystallization from process-induced amorphization.

(c) 2007 Wiley-Liss, Inc. and the American Pharmacists Association J Pharm Sci 96:1147-1158, 2007

Keywords: thermal analysis; cocrystals; complexation; crystal engineering; crystallization; amorphous; microscopy
\end{abstract}

\section{INTRODUCTION}

Understanding the thermodynamic, kinetic, and molecular phenomena that determine crystalliza-

Correspondence to: Naír Rodríguez-Hornedo (Telephone: 734-763-0101; Fax: 734-615-6162; E-mail: nrh@umich.edu)

Journal of Pharmaceutical Sciences, Vol. 96, 1147-1158 (2007)

(C) 2007 Wiley-Liss, Inc. and the American Pharmacists Association tion events has been of great importance in the pharmaceutical area to meet the safety and efficacy requirements of pharmaceutical products. ${ }^{1-6}$ The success of applying fundamental concepts has been demonstrated in directing crystallization outcomes from liquid phases, ${ }^{7-9}$ and in preventing crystallization from solid amorphous phases. ${ }^{2-4,6,10,11}$ Among the repertoire of 
noncovalent interactions inherent to molecular recognition, hydrogen bonds because of their strength and directionality have been shown to drive molecular associations that lead to crystalline or noncrystalline solids. ${ }^{11-14}$ Hydrogen-bond motifs revealed by molecular arrangements in single component and multiple component crystals (cocrystals) ${ }^{15-18}$ have also contributed to directed nucleation of polymorphs, solvates, and cocrystals. $8,9,14,19-23$ Hydrogen bonds are thus a common feature for the formation of molecular complexes and networks that facilitate or prevent crystallization.

Cocrystals are multiple component crystals that often rely on hydrogen bonds between neutral molecules. Therefore, cocrystallization requires that molecular associations between different components, or heteromers, be more favorable than those between the same components, or homomers. ${ }^{15,16}$ It is important to note that a cocrystal is a single phase of multiple components and not a mixture of single component crystalline phases. Cocrystallization is attractive because it enables the modification and engineering of important physicochemical properties, such as solubility, dissolution rate, bioavailability, hygroscopicity, morphology, compaction, and melting point. $^{14,18,19,24-27}$ While pharmaceutical cocrystals have been discovered by liquid and solid-state processes, ${ }^{18,27-29}$ the mechanisms and kinetics of formation have received little attention.

Earlier reports from our laboratory show that cocrystal formation from solution is explained by solution chemistry models and that supersaturation with respect to cocrystal is generated by dissolving nonequivalent amounts of cocrystal components. ${ }^{20,21}$ The mechanisms for spontaneous cocrystal formation in aqueous and organic media have been described and applications to cocrystallization methods have been presented. ${ }^{21}$

Cogrinding solid reactants has been an attractive method to screen for cocrystals and is a way to circumvent the large number of experimental variables involved in solution processes. ${ }^{15,16,30-33}$ Phase transformations induced by grinding or milling have been thoroughly studied in the pharmaceutical literature. ${ }^{34-38}$ These transformations are often accompanied by solid-state disorder and include polymorphic transformations, proton transfer reactions, complexation, and cocrystallization. We have recently demonstrated that cocrystallization can proceed during storage after mechanical activation of the reactants and that the reaction is associated with the propensity of crystalline reactants to form disordered or amorphous phases during mechanical stress. ${ }^{39,40}$ The present work is part of a study to understand the factors that control amorphous phase-mediated cocrystallization. Key questions that will be addressed are whether amorphous phases lead to cocrystal formation and if there is a relation between temperature and crystallization pathways.

The carbamazepine-nicotinamide cocrystal (CBZ-NCT) with a 1:1 molar ratio was used as a model system to study the crystallization behavior above the glass transition temperature of equimolar amorphous phases prepared by melt quenching. The molecular arrangement showing the hydrogen bond motifs between these two components in the CBZ-NCT cocrystal prepared from solvent or by room temperature cogrinding $^{18,20,21,39}$ is presented in Figure 1. Crystallization pathways and kinetics were determined by studying the thermal behavior of amorphous phases of reactants by using hotstage polarized microscopy (HSPM), hot-stage Raman microscopy (HSRM), differential scanning calorimetry (DSC), and X-ray powder diffraction (XRPD).

\section{MATERIALS AND METHODS}

\section{Materials}

Carbamazepine monoclinic (CBZ(III), $\quad T_{\mathrm{m}}=$ $178^{\circ} \mathrm{C}$ ) and nicotinamide (NCT(I), $\left.T_{\mathrm{m}}=128^{\circ} \mathrm{C}\right)$ were purchased from Sigma (Milwaukee, WI) and were used as received. CBZ-NCT cocrystals (CBZ-NCT(I)) were prepared from solution by the methods described by Nehm et al. ${ }^{20,21}$

Amorphous equimolar phases were prepared by quenching the melted cocrystal of CBZ-NCT(I) in situ in DSC pans and on a controlled temperature microscope stage as described in the sections below. Since the cocrystal has a melting temperature of $158^{\circ} \mathrm{C},{ }^{24,25}$ about $20^{\circ} \mathrm{C}$ lower than that of the monoclinic form of CBZ (III), it allows for melting without significant chemical degradation of CBZ.

\section{Methods}

\section{Differential Scanning Calorimetry}

DSC was performed on a TA Instruments (New Castle, DE) Q1000 DSC with refrigerated cooling system. The DSC was calibrated for temperature 


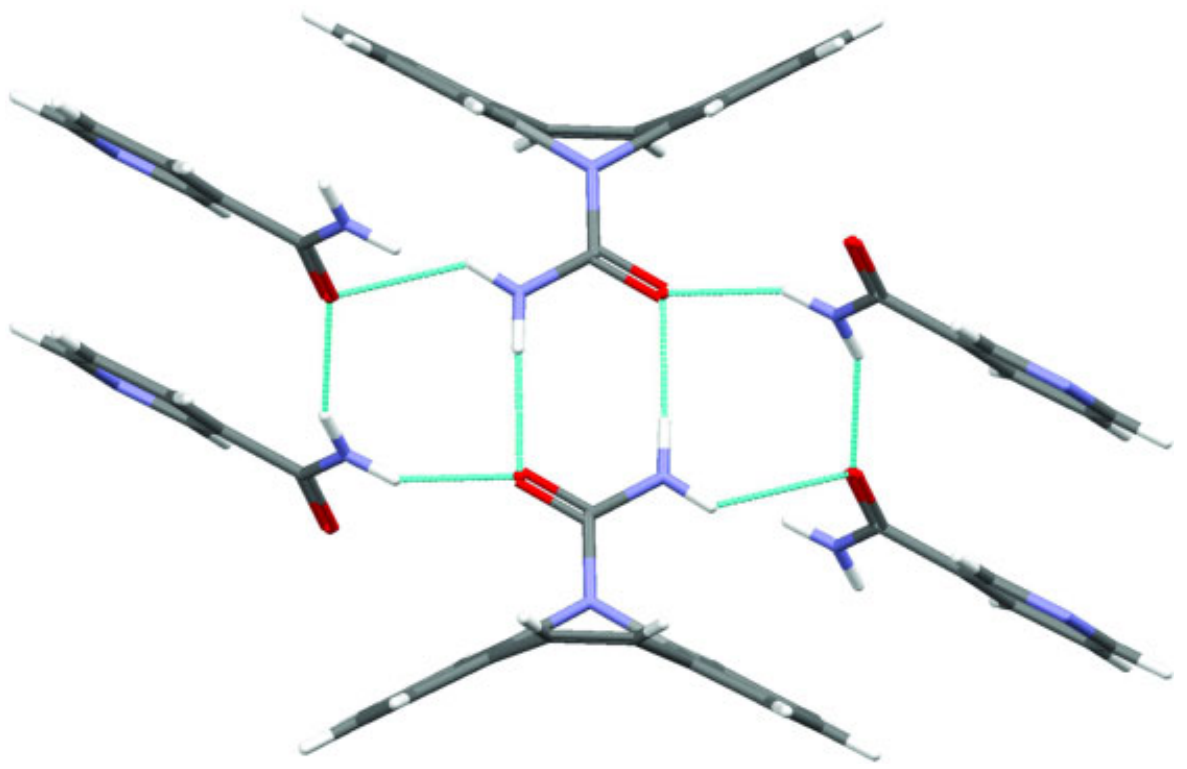

Figure 1. Hydrogen bonds between $\mathrm{NH}$ and $\mathrm{C}=\mathrm{O}$ of amide groups in the carbamazepine-nicotinamide cocrystal CBZ-NCT (I).

and cell constants using indium. The samples were continuously purged with $\mathrm{N}_{2}$ at $50 \mathrm{~mL} / \mathrm{min}$. DSC data were collected in triplicate, nonisothermally at ramping rates between 0.5 and $30^{\circ} \mathrm{C} / \mathrm{min}$, and isothermally at temperatures of 56,61 , and $66^{\circ} \mathrm{C}$. Samples of $2-7 \mathrm{mg}$ were weighed and sealed in crimped aluminum pans. Amorphous samples were prepared in situ by heating CBZNCT(I) just past the $158^{\circ} \mathrm{C}$ melt and cooling at $20^{\circ} \mathrm{C} / \mathrm{min}$ down to $-30^{\circ} \mathrm{C}$. Temperatures reported are onset temperatures unless otherwise specified.

\section{Hot-Stage Polarized Optical Microscopy}

HSPM studies were conducted on a Leica DMPL polarizing optical microscope (Leica Microsystems Wetzlar GmbH, Wetzlar, Germany) and a Linkham THMS600 hot stage with liquid nitrogen cooling (Linkham Scientific Instruments Ltd, Surry, England). A full wave compensator plate was used with cross polarizing filters to enhance the optical features of some of the samples, while collection without the compensator plate was performed for crystallization kinetics data. Images were collected with a Spot Insight FireWire 4 Megasample Color Mosaic camera controlled with Spot software (Diagnostics Inc, Sterling Heights, MI).

Amorphous samples for HSPM studies were prepared in situ by placing 1-3 mg of CBZ-NCT(I) between two borosilicate glass windows in the hot stage. The samples were then subjected to a temperature program that would allow complete melting prior to quenching to $-20^{\circ} \mathrm{C}$ at $125^{\circ} \mathrm{C} /$ min. The resulting amorphous material was then either heated to a selected temperature for isothermal studies or heated through the melt at a specified heating rate for nonisothermal studies.

\section{X-Ray Powder Diffraction}

XRPD patterns were collected on an X-ray diffractometer (Rigaku Ultima-plus, Tokyo, Japan) with $\mathrm{Cu} \mathrm{K}$-alpha radiation operating at $30 \mathrm{kV}$ and $15 \mathrm{~mA}$. Samples were scanned from $3^{\circ}$ to $50^{\circ} 2-\Theta$ at a step size of $0.04^{\circ} 2-\Theta$ and at $2.4 \mathrm{~s}$ per step.

\section{Hot-Stage Raman Microscopy}

Raman spectroscopy was carried out using a Kaiser Optical Systems (Ann Arbor, MI) HoloLab series 5000 Raman spectrometer equipped with a $300 \mathrm{~mW}$ external cavity stabilized diode laser operating at $785 \mathrm{~nm}$. A Leica DMLP microscope was used in conjunction with a Mettler-Toledo (Columbus, OH) F82 hot stage for temperature control. Raman spectra were collected in back scattering geometry using sample sizes of $1-3 \mathrm{mg}$. Amorphous samples were prepared between a polished aluminum base and a quartz cover slip in the hot stage using the method described in the HSPM section. The spectra had a $4 \mathrm{~cm}^{-1}$ 
resolution and were collected between 100 and $3200 \mathrm{~cm}^{-1}$.

\section{Image-Based Crystallization Analysis}

Crystallization kinetic data from the amorphous films of CBZ and NCT were obtained by analyzing images collected from HSPM in a manner derived from methods based on total transmitted sample intensity. ${ }^{41}$ The microscope was set up with the polarizer and analyzer completely crossed without the use of the full-wave compensator. This configuration allowed the amorphous regions to appear black. A $10 \times$ objective was used to maximize the observed area within the constraint of the light path of the hot stage. The recorded images represented a $1.5 \times 1.5 \mathrm{~mm}^{2}$ area. Initial light intensities of the amorphous materials were adjusted to be just above the threshold of detection on the CCD camera to be sure changes in transmission could be recorded, even at the lowest levels. Images were collected at time intervals, typically every 15,30 , or $60 \mathrm{~s}$.

The sequence of images was analyzed with Image $J^{42}$ software by generating a histogram of pixel intensities for each image in the sequence. The initial image acted as the calibration, setting the initial intensity range that was considered to be black. The black pixel count from each image was then used to calculate the amorphous content. Since anything that was not black was considered crystalline, the crystal fraction was computed from the following equation:

$$
\alpha_{t}=1-\frac{\text { "black" pixels at time }=t}{\text { "black" pixels at time }=0}
$$

A nonlinear least-squares fit of a suitable crystallization model to the data resulted in kinetic and mechanistic information.

\section{DSC-Based Crystallization Analysis}

Isothermal experiments carried out on the DSC exhibited time-dependent exothermic events due to crystallization. These events were analyzed and kinetic parameters were determined by computing a running integral across the event by a method similar to that described by Zhou et al. ${ }^{3}$ The crystal fraction, $\alpha$, was then obtained by normalizing the integral. Models were then evaluated based on best fit to the data to obtain kinetic information.

Nonisothermal experiments were also performed to compare thermal characteristics under differing conditions. These experiments utilized the Kissinger method of analysis ${ }^{43}$ via the following equation:

$$
\ln \left(\frac{\beta}{T_{\mathrm{c}}^{2}}\right)=\ln \left(\frac{A R}{E_{\mathrm{a}}}\right)-\frac{E_{\mathrm{a}}}{R T_{\mathrm{c}}}
$$

where $\beta$ is the heating rate, $T_{\mathrm{c}}$ is the peak crystallization temperature, $A$ is the frequency factor, $R$ is the gas constant, and $E_{\mathrm{a}}$ is the activation energy. From the plot of $1 / T_{\mathrm{c}}$ versus. $\ln \left(\beta / T_{\mathrm{c}}^{2}\right)$, the slope provides $E_{\mathrm{a}}$, and the intercept provides $A$.

\section{RESULTS AND DISCUSSION}

Thermal analysis of the CBZ-NCT (I) cocrystal prepared from liquid solutions shows a single endothermic event at $158^{\circ} \mathrm{C}$ (Fig. 2a). This event is due to the melt of the cocrystal. Amorphous equimolar phases of CBZ and NCT were prepared in situ by quenching the melt of CBZ-NCT(I) cocrystal to ensure a uniform distribution of components. Cooling rates as slow as $20^{\circ} \mathrm{C} / \mathrm{min}$ resulted in the formation of an amorphous phase as indicated by the lack of birefringence on

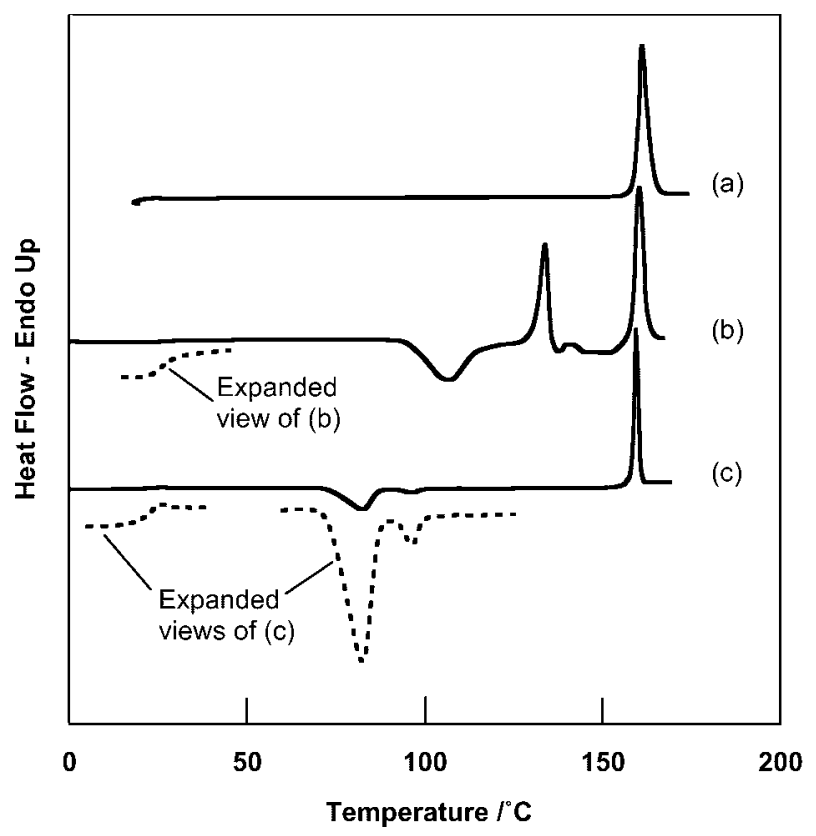

Figure 2. DSC results showing thermal behavior during heating (a) cocrystal prepared from solution CBZ-NCT(I), (b) amorphous equimolar phase of CBZ and NCT at $10^{\circ} \mathrm{C} / \mathrm{min}$, and (c) amorphous equimolar phase of $\mathrm{CBZ}$ and $\mathrm{NCT}$ at $3^{\circ} \mathrm{C} / \mathrm{min}$. Dashed lines are expanded views for clarity. 
polarized light microscopy studies and the glass transition temperature shown in Figure $2 b$ and c. Thermal analysis of these amorphous phases at heating rates of 3 and $10^{\circ} \mathrm{C} / \mathrm{min}$ shows a glass transition at $19-22^{\circ} \mathrm{C}$ followed by different events. At a heating rate of $10^{\circ} \mathrm{C} / \mathrm{min}$ the thermogram in Figure $2 \mathrm{~b}$ shows an exotherm at $87^{\circ} \mathrm{C}$, an endotherm at $125-128^{\circ} \mathrm{C}$ followed immediately by an exotherm, and finally the endothermic melt of the cocrystal $\mathrm{CBZ}-\mathrm{NCT}(\mathrm{I})$ at $158^{\circ} \mathrm{C}$. The thermogram in Figure 2c at the lower heating rate of $3^{\circ} \mathrm{C} / \mathrm{min}$ exhibits different behavior with two exothermic events at $67^{\circ} \mathrm{C}$ and $95^{\circ} \mathrm{C}$ followed by the $158^{\circ} \mathrm{C}$ melt of the cocrystal.

Crystallization from the amorphous phase of CBZ and NCT was also investigated by HSPM under isothermal conditions at 41, 61, 81, and $95^{\circ} \mathrm{C}$. Amorphous materials were prepared in situ on the hot stage and the samples were examined by image analysis. The photomicrographs in Figure 3 were collected during these experiments and show various stages of crystallization from the amorphous phase. A crystallization event from the amorphous state is first observed by the birefringent phase that nucleates and grows as shown in Figure 3 (upper left and right) at $41^{\circ} \mathrm{C}$ and $61^{\circ} \mathrm{C}$. This initial phase subsequently transforms to another form as shown in Figure 3 (lower left and right) at $81^{\circ} \mathrm{C}$ and $95^{\circ} \mathrm{C}$. The transformation front, noted by the arrows in Figure 3, continued to move across the viewable region until the entire sample was transformed. A single melt was observed from this transformed material at $158-162^{\circ} \mathrm{C}$ upon subsequent heating at $10^{\circ} \mathrm{C} / \mathrm{min}$. The crystals formed at 41 and $61^{\circ} \mathrm{C}$ did not show any transformation under isothermal conditions within 24 and $3 \mathrm{~h}$, respectively, but did exhibit a transformation similar to that observed at 81 and $95^{\circ} \mathrm{C}$ upon heating at $10^{\circ} \mathrm{C} / \mathrm{min}$ that was then followed by a single melt at $158-162^{\circ} \mathrm{C}$.

In order to gain more information about the phase transformations, Raman microscopy
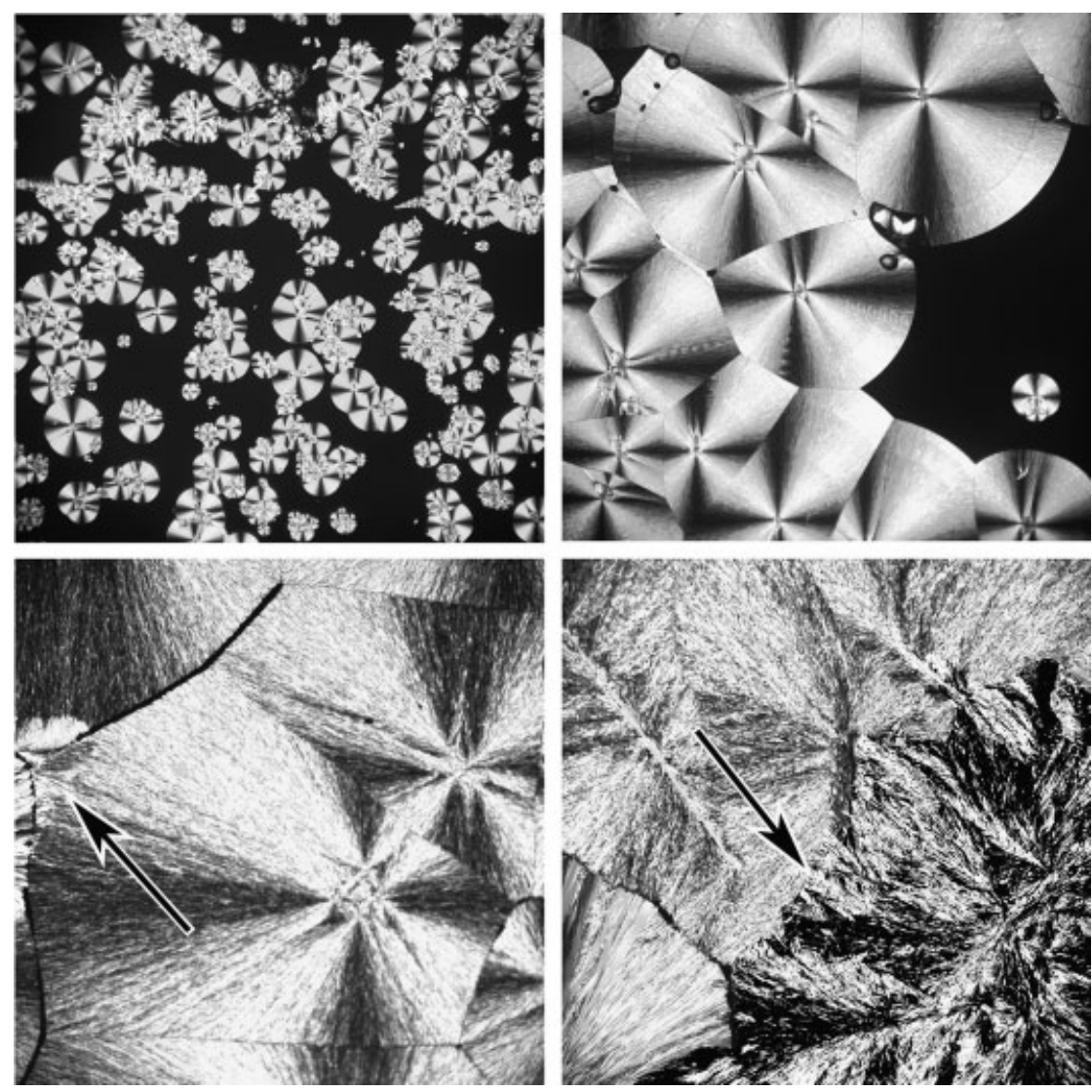

Figure 3. Photomicrographs of isothermal crystallization from amorphous equimolar phase of CBZ and NCT at $41^{\circ} \mathrm{C} / 16 \mathrm{~h}$ (upper left), $61^{\circ} \mathrm{C} / 90 \mathrm{~min}$ (upper right), $81^{\circ} \mathrm{C} / 30 \mathrm{~min}$ (lower left), and $95^{\circ} \mathrm{C} / 30 \mathrm{~min}$ (lower right). Note the solid-solid transformation front indicated by the arrows in the 81 and $95^{\circ} \mathrm{C}$ images. 
studies were carried out isothermally at $61^{\circ} \mathrm{C}$ on the hot stage with similar configuration to that used in the HSPM studies. As shown in Figure 4 the Raman spectrum of the phase initially crystallized is different from that of the single component crystals CBZ(III) and NCT(I). The shift in the spectral peaks from $1038 \mathrm{~cm}^{-1}$ for the amorphous phase to $1042 \mathrm{~cm}^{-1}$ for this solid phase and back to $1036 \mathrm{~cm}^{-1}$ for CBZ-NCT(I) precludes the possibility that this initial solid phase was a mixture of amorphous phase and CBZ-NCT(I) cocrystal. This indicates that the initial phase is different from CBZ-NCT(I) and the amorphous phase of CBZ and NCT.

The time dependence of XRPD patterns showing crystallization from the amorphous phase of $\mathrm{CBZ}$ and NCT at $61^{\circ} \mathrm{C}$ is presented in Figure 5. For reference, the XRPD pattern for $\mathrm{CBZ}-\mathrm{NCT}(\mathrm{I})$ prepared from solution is also presented. The patterns in the early stages of the process show broad peaks of low intensities indicating a partially crystalline sample. There are also peaks at $5.6^{\circ}$ and $8.7^{\circ} 2 \Theta$ that do not appear in the XRPD pattern of the reference cocrystal of CBZ-NCT (I). Clear trends can be observed in the development of peaks during the experiment that suggest an intermediate phase, which we are referring to as CBZ-NCT(II), that precedes the formation of the stable phase of the cocrystal CBZ-NCT(I).

The thermal events associated with the transition from CBZ-NCT form II to form I are shown in

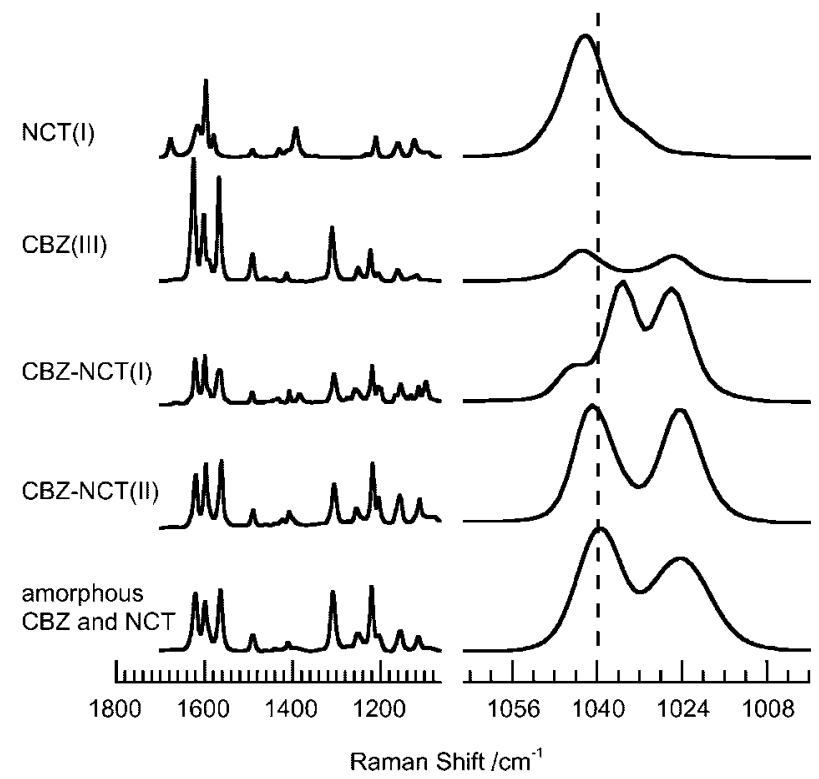

Figure 4. Raman spectra comparing single component crystals, cocrystals, and amorphous equimolar phase of CBZ and NCT.

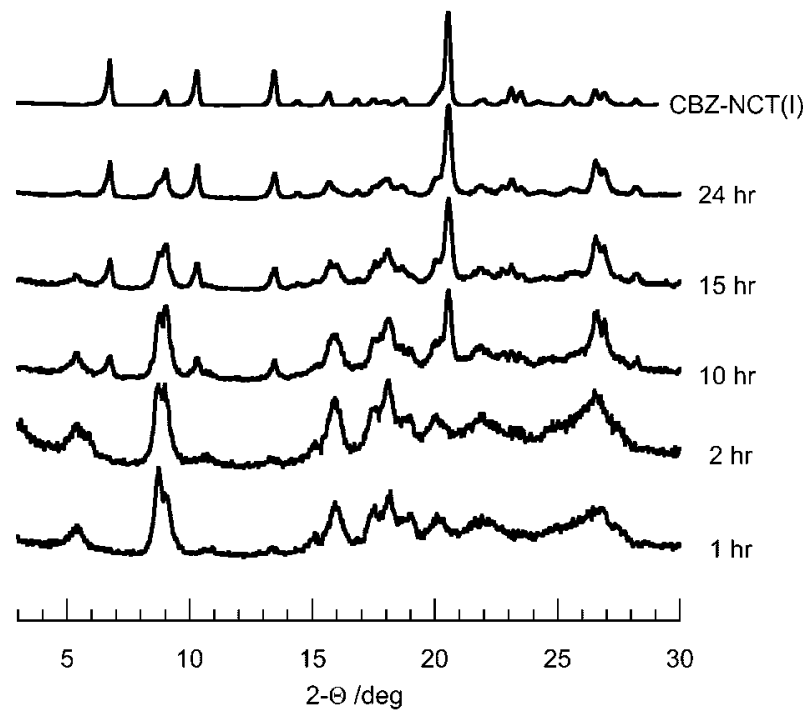

Figure 5. XRPD diffraction patterns showing the time course for crystallization from the amorphous phase of CBZ and NCT at $61^{\circ} \mathrm{C}$. For reference, the XRPD pattern for CBZ-NCT(I) prepared from solution is also included.

Figure 6. An exothermic transition is observed at $83-90^{\circ} \mathrm{C}$ with an enthalpy of 8.1-11.1 $\mathrm{J} / \mathrm{g}$ when CBZ-NCT(II) is heated at a rate of $3-20^{\circ} \mathrm{C} / \mathrm{min}$, respectively. This indicates that there is a monotropic relationship between these forms. ${ }^{44}$ Studies

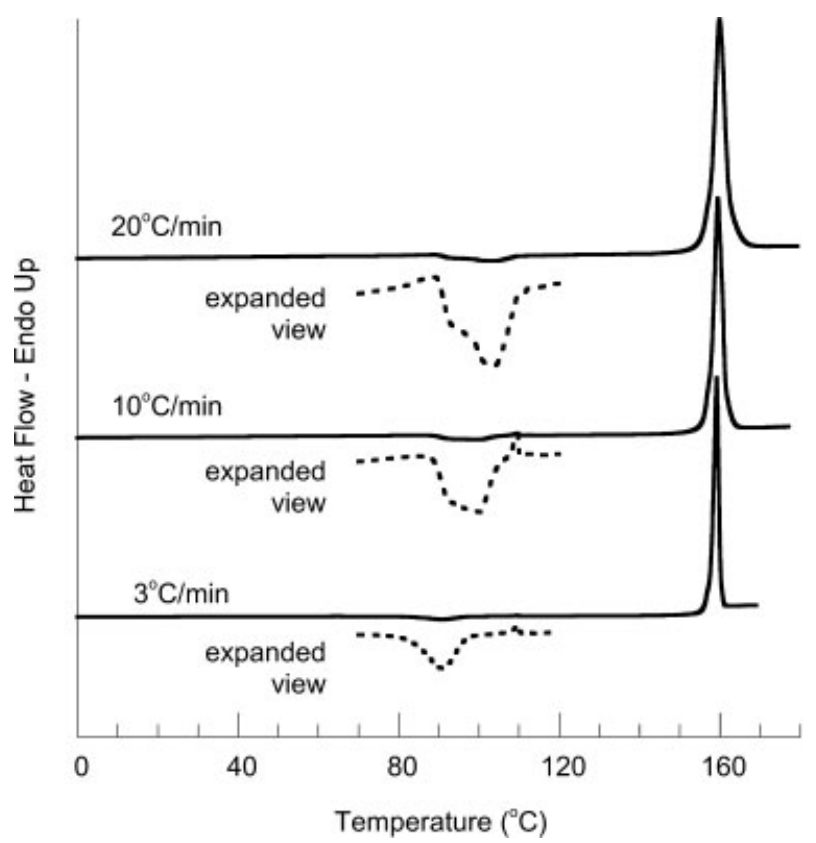

Figure 6. DSC results showing the thermal behavior of CBZ-NCT (II) indicating the exothermic transition to CBZ-NCT(I) followed by the melt of form (I). 
to confirm the structure of this new phase continue in our laboratory.

Two different cocrystallization pathways from the amorphous phase were identified under high and low heating rates. Figure 7 shows the DSC thermogram and photomicrographs from HSPM for the cocrystallization pathway observed at $10^{\circ} \mathrm{C} / \mathrm{min}$. This is characterized by the crystallization of single component phases of CBZ and NCT at $87^{\circ} \mathrm{C}$. These events were followed by the melting of $\mathrm{NCT}(\mathrm{I})$ at $125^{\circ} \mathrm{C}$, dissolution of CBZ into this melt, crystallization of CBZ-NCT(I), and the melting of CBZ-NCT(I) at $158^{\circ} \mathrm{C}$. A slower heating rate of $3{ }^{\circ} \mathrm{C} / \mathrm{min}$ resulted in a different pathway as shown in Figure 8. The crystallization of CBZNCT(II) at $72^{\circ} \mathrm{C}$ is followed by an exothermic transition to CBZ-NCT(I) at $87^{\circ} \mathrm{C}$ and the melt of $\mathrm{CBZ}-\mathrm{NCT}(\mathrm{I})$ at $158^{\circ} \mathrm{C}$.

The kinetics of isothermal crystallization of CBZ-NCT (II) from the amorphous phase using the data from the automated HSPM method $(n=3)$ are presented in Figure 9. Results at $81^{\circ} \mathrm{C}$ and $95^{\circ} \mathrm{C}$ are highly reproducible, however, a wide spread in the data was observed at $61^{\circ} \mathrm{C}$. This is a result of the slower crystallization rates at $61^{\circ} \mathrm{C}$, the intrinsic distribution of induction times for nucleation, and the limited field of view of the microscope relative to the total sample area.

The exothermic events corresponding to crystallization of CBZ-NCT(II) from the amorphous phase at 56, 61, and $66^{\circ} \mathrm{C}$ measured during isothermal DSC studies are presented in Figure 10. The crystallization results from the $61^{\circ} \mathrm{C}$ study are plotted along with the HSPMderived data for comparison in Figure 11. The superior reproducibility of the DSC kinetic data is shown here and is the reason for using DSC data for quantitative crystallization analysis. Note here that this is not a reason to abandon HSPM methodology for kinetics investigation, however, since HSPM can provide important qualitative information that simply cannot be captured or interpreted from DSC only.

The automated HSPM method for monitoring crystallization was used in this study and complemented well the DSC analysis. In fact, HSPM provided the first evidence of a phase transition after the initial crystallization of CBZ-NCT(II). Figure 12 shows a composite of approximately 150 individual images captured from one completely crystallized sample, $16 \mathrm{~mm}$ in diameter. The accompanying graphic depicts the nucleation centers with the small black square indicating the relative size of the field of view to the entire sample. Visual inspection reveals that many random samples would be required to obtain a representative average from the distribution of the 997 nucleation sites in this case. Therefore, the combination of both macro and micro methods of analysis provides mechanistic and kinetic information that is representative of the system under consideration.

The fraction crystallized as a function of time based on DSC studies at 56,61 , and $66^{\circ} \mathrm{C}$ is shown in Figure 13. An $r^{2}$ analysis of least-squares fit of various models (see Table 1) showed that the Avrami-Erofeev model with an exponent value of

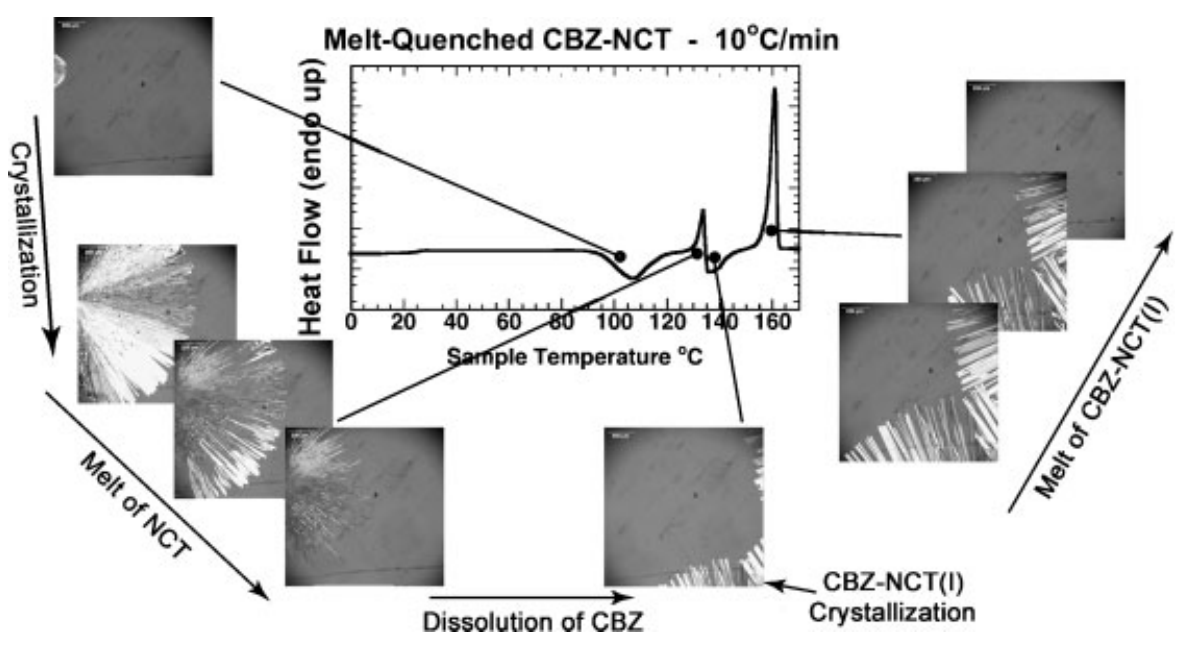

Figure 7. DSC and HSPM results during nonisothermal crystallization studies of amorphous phase of $\mathrm{CBZ}$ and $\mathrm{NCT}$ at $10^{\circ} \mathrm{C} / \mathrm{min}$. 


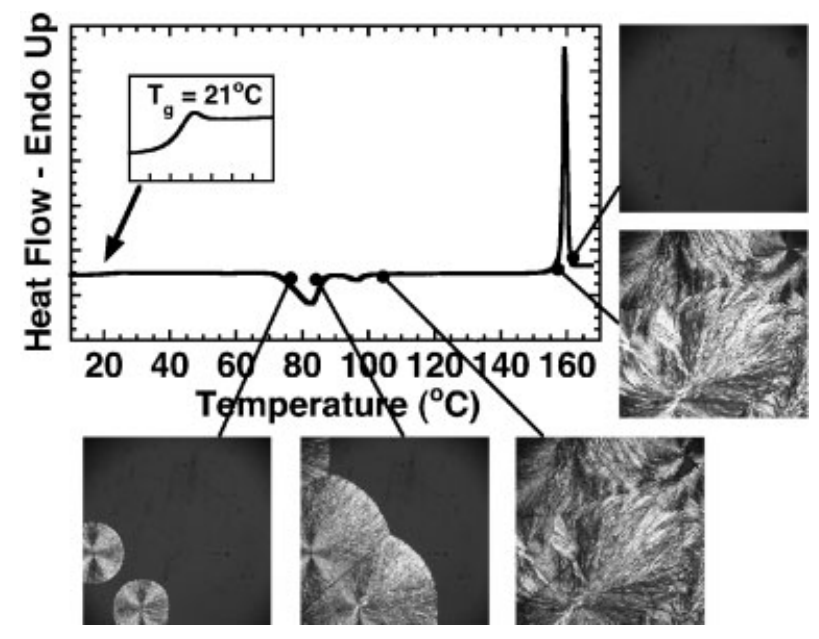

Figure 8. DSC and HSPM results during nonisothermal crystallization studies of amorphous phase of CBZ and $\mathrm{NCT}$ at $3^{\circ} \mathrm{C} / \mathrm{min}$.

3 best describes the results. The Avrami-Erofeev model used was:

$$
\alpha=1-e^{-(k t)^{n}}
$$

where $k$ is the rate constant and $n$ is the exponent. Activation energy, $E_{\text {a }}$, for the crystallization of CBZ-NCT (II) was determined to be $61 \mathrm{~kJ} / \mathrm{mol}$ over the temperature range of $56-66^{\circ} \mathrm{C}$ using the rate constants evaluated from the AvramiEerofev model in an Arrhenius analysis.

A Kissinger plot was constructed to further investigate crystallization kinetics from noni-

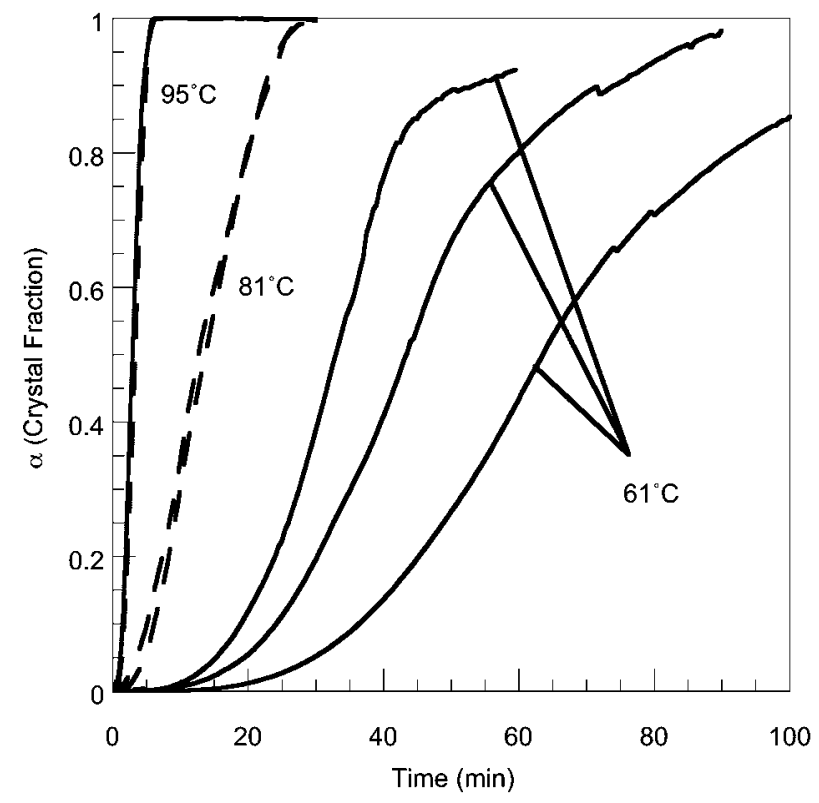

Figure 9. Isothermal HSPM-derived crystallization data at 61,81 , and $95^{\circ} \mathrm{C}$.

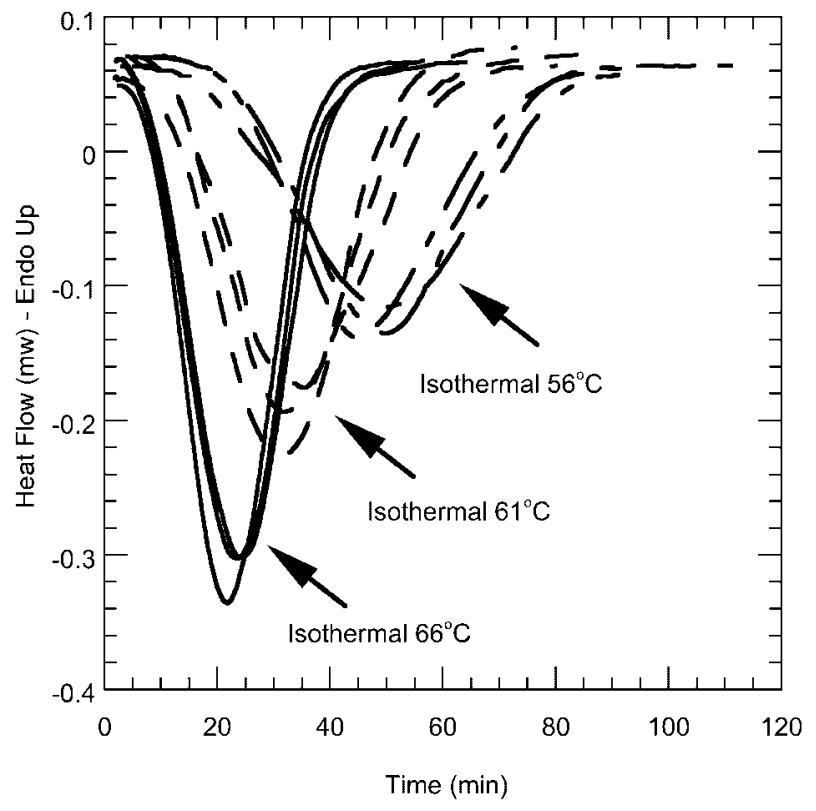

Figure 10. Isothermal DSC thermograms during crystallization from the amorphous phase at 56,61 , and $66^{\circ} \mathrm{C}$.

sothermal DSC with ramp rates between 0.5 and $25^{\circ} \mathrm{C} / \mathrm{min}$ and is presented in Figure 14. This plot shows two distinct, linear regions that correlate with the crystallization of CBZ-NCT(II) (steeper slope) or the crystallization of individual components. The transition between these two pathways occurs at $9.7^{\circ} \mathrm{C} / \mathrm{min}$ heating rate. From

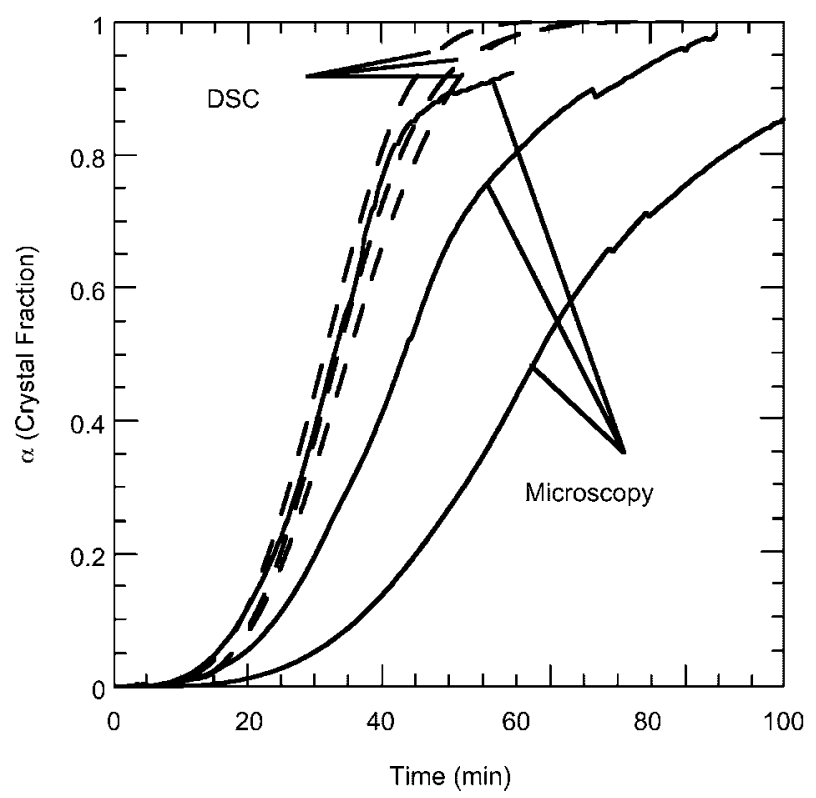

Figure 11. Comparison of crystallization kinetics measured in DSC and HSPM at $61^{\circ} \mathrm{C}$. 


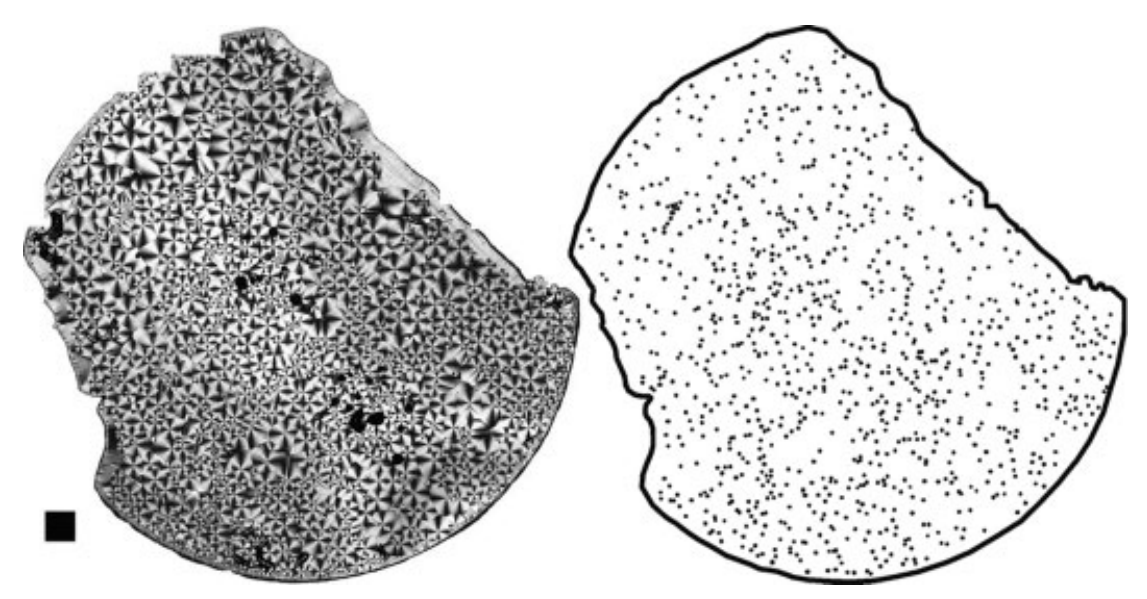

Figure 12. Composite image of crystallized CBZ-NCT(II) from the amorphous phase. Black square represents $1.5 \times 1.5 \mathrm{~mm}^{2}$ viewing area available for HSPM. The graphic on the right shows the distribution of 997 nucleation points.

the slopes, the $E_{\mathrm{a}}$ was calculated to be $37.6 \mathrm{~kJ} / \mathrm{mol}$ and $83.4 \mathrm{~kJ} / \mathrm{mol}$ for the crystallization of CBZ and NCT individually and for the crystallization of CBZ-NCT(II), respectively.

The transformation from the amorphous to cocrystalline form (II) to form (I) was studied under isothermal conditions at $61^{\circ} \mathrm{C}$ by hot stage Raman microscopy and the results of triplicate experiments are shown in Figure 15. The peak intensity at $1040 \mathrm{~cm}^{-1}$ was used to follow the conversion because there are significant differences near this peak position between the three forms (amorphous-1038 $\mathrm{cm}^{-1}$, CBZNCT(II)-1042 $\mathrm{cm}^{-1}$, CBZ-NCT(I)-1036 $\mathrm{cm}^{-1}$ ).

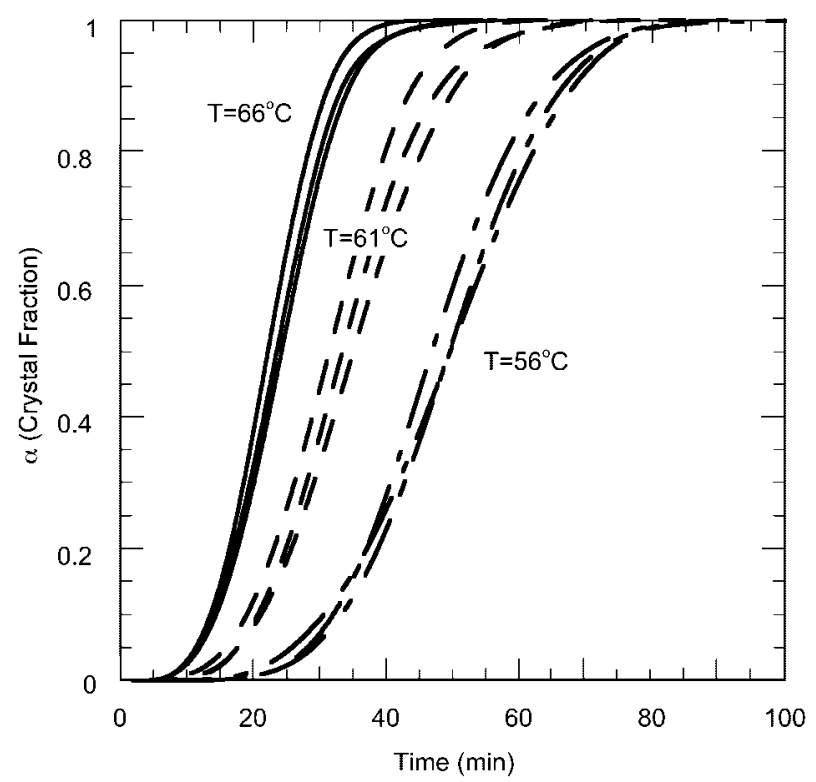

Figure 13. DSC derived crystallization data from isothermal studies at 56,61 , and $66^{\circ} \mathrm{C}$.
The peak intensity at $1040 \mathrm{~cm}^{-1}$ was normalized using the consistent peak at $1306 \mathrm{~cm}^{-1}$. These results are in good agreement with those of DSC and HSPM studies. The time scale for the initial crystallization of CBZ-NCT(II) was the same as that observed by DSC and HSPM. The transformation rate for CBZ-NCT (II) to (I) was constant in these experiments as indicated by the parallel trends in the decrease of peak ratios with time. The induction times for nucleation of form (I), however, varied noticeably. This distribution of induction times is inherent to the small sampling area and conditions where nucleation events are widely distributed as observed in HSPM studies.

Table 1. Evaluation of Kinetic Models to Describe Isothermal Cocrystallization from Amorphous Equimolar Phase of CBZ and NCT Determined by DSC

\begin{tabular}{lc}
\hline Model/Mechanism & $r^{2}$ \\
\hline Avrami-Erofeev $n=3$ & 0.9894 \\
One-dimensional diffusion & 0.9074 \\
Two-dimensional diffusion & 0.9093 \\
Three-dimensional diffusion (Jander) & 0.8602 \\
Three-dimensional diffusion & 0.9059 \\
$\quad$ Ginstling-Brounshtein) & \\
First-order reaction & 0.8372 \\
Random nucleation (Prout-Tompkins) & 0.9581 \\
Power law ( $n=1 / 2)$ & 0.8790 \\
Power law ( $n=1 / 3)$ & 0.8410 \\
Power law $(n=1 / 4)$ & 0.8074 \\
One-dimensional phase boundary & 0.9129 \\
$\quad$ reaction (zero order) & \\
Two-dimensional phase boundary reaction & 0.9531 \\
Three-dimensional phase boundary reaction & 0.9525 \\
\hline
\end{tabular}




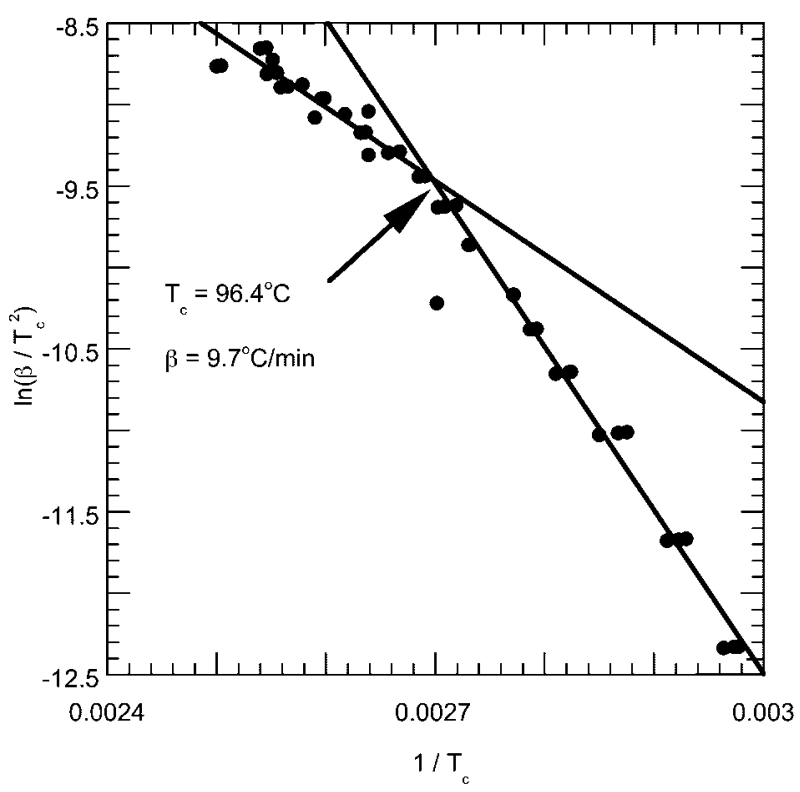

Figure 14. Kissinger plot of crystallization from amorphous CBZ and NCT mixture. Note change of slopes for the two pathways at $9.7^{\circ} \mathrm{C} / \mathrm{min}$ heating rate.

\section{CONCLUSIONS}

The results presented here show that amorphous phases generate cocrystals and that thermal history affects crystallization pathways in significant ways. Studies of amorphous films and small samples of equimolar composition of carbamaze-

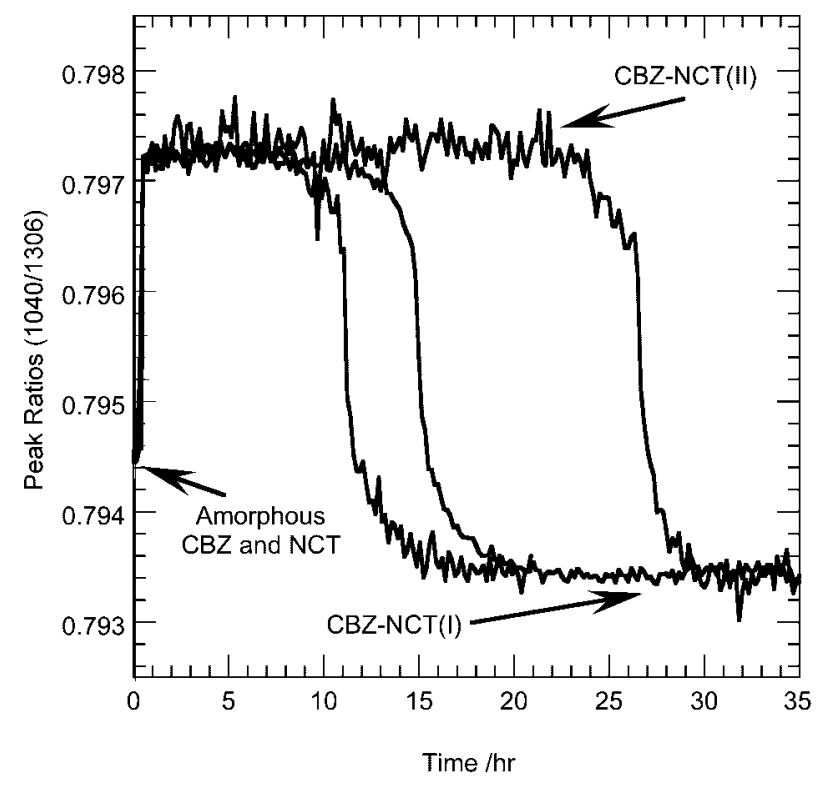

Figure 15. Time-resolved Raman microspectroscopy results at $61^{\circ} \mathrm{C}$ showing the CBZ-NCT(II) crystallization from amorphous phase and subsequent transformation to CBZ-NCT(I). pine and nicotinamide were carried out under nonisothermal and isothermal conditions. Thermal microscopy (polarized light microscopy and Raman microscopy), thermal analysis (DSC), and XPRD methods were valuable tools in identifying the crystallization behavior and kinetics. During nonisothermal studies two different pathways to cocrystal formation from the amorphous phase were identified: (1) at low heating rates a metastable cocrystalline phase initially nucleates and transforms to the more stable cocrystalline phase of CBZ-NCT, and (2) at higher heating rates individual components crystallize, then melt and the stable cocrystalline phase nucleates and grows from the melt. Isothermal studies above the $T_{\mathrm{g}}$ of the amorphous equimolar phase also confirm the nucleation of a metastable cocrystalline phase and a solid phase mediated transformation to the stable cocrystalline phase. Cocrystallization kinetics were measured by image analysis and by thermal analysis from small samples and are described by the Avrami-Erofeev model. These findings have important implications for the use of amorphous phases for the discovery of cocrystals and to identify the propensity of cocrystallization from amorphous phases induced by pharmaceutical processes.

\section{ACKNOWLEDGMENTS}

Technical assistance of Siwei Ding is acknowledged. We acknowledge partial funding from Pfizer, Ann Arbor, MI and from the Purdue/ Michigan Consortium on Supramolecular Assemblies and Solid State Properties of Pharmaceuticals.

\section{REFERENCES}

1. Vippagunta SR, Brittain HG, Grant DJW. 2001. Crystalline solids. Adv Drug Del Rev 48:3-26.

2. Vippagunta SR, Maul KA, Tallavajhala S, Grant DJW. 2002. Solid-state characterization of nifedipine solid dispersions. Int J Pharm 236:111-123.

3. Zhou DL, Schmitt EA, Zhang GG, Law D, Vyazovkin S, Wight CA, Grant DJW. 2003. Crystallization kinetics of amorphous nifedipine studied by modelfitting and model-free approaches. J Pharm Sci 92:1779-1792.

4. Zhou DL, Zhang GGZ, Law D, Grant DJW, Schmitt EA. 2002. Physical stability of amorphous pharmaceuticals: Importance of configurational 
thermodynamic quantities and molecular mobility. J Pharm Sci 91:1863-1872.

5. Hosokawa T, Datta S, Sheth AR, Grant DJW. 2004. Relationships between crystal structures and thermodynamic properties of phenylbutazone solvates. Cryst Eng Comm 6:243-249.

6. Hancock BC, Zografi G. 1994. The relationship between the glass transition temperature and the water content of amorphous pharmaceutical solids. Pharm Res 11:471-477.

7. Datta S, Grant DJW. 2005. Computing the relative nucleation rate of phenylbutazone and sulfamerazine in various solvents. Cryst Growth Des 5: 1351-1357.

8. Gu CH, Chatterjee K, Young V, Grant DJW. 2002. Stabilization of a metastable polymorph of sulfamerazine by structurally related additives. J Cryst Growth 235:471-481.

9. Gu CH, Young V, Grant DJW. 2001. Polymorph screening: Influence of solvents on the rate of solvent-mediated polymorphic transformation. J Pharm Sci 90:1878-1890.

10. Lu Q, Zografi G. 1998. Phase behavior of binary and ternary amorphous mixtures containing indomethacin, citric acid, and PVP. Pharm Res 15: 1202-1206.

11. Taylor LS, Zografi G. 1997. Spectroscopic characterization of interactions between PVP and Indomethacin in amorphous molecular dispersions. Pharm Res 14:1691-1698.

12. Adsmond DA, Grant DJW. 2001. Hydrogen bonding in sulfonamides. J Pharm Sci 90:2058-2077.

13. Dong ZD, Munson EJ, Schroeder SA, Prakash I, Grant DJW. 2002. Conformational flexibility and hydrogen-bonding patterns of the neotame molecule in its various solid forms. J Pharm Sci 91:2047-2056.

14. Rodríguez-Spong B, Price CP, Jayasankar A, Matzger AJ, Rodríguez-Hornedo N. 2004. General principles of pharmaceutical solid polymorphism: A supramolecular perspective. Adv Drug Del Rev 56: 241-274.

15. Etter MC, Reutzel SM. 1991. Hydrogen bond directed cocrystallization and molecular recognition properties of acyclic imides. J Am Chem Soc 113:2586-2598.

16. Etter MC, Frankenbach GM. 1989. Hydrogen-bond directed cocrystallization as a tool for designing acentric organic solids. Chem Mater 1:10-12.

17. Desiraju GR. 2002. Hydrogen bridges in crystal engineering: Interactions without borders. Acc Chem Res 35:565-573.

18. Fleischman SG, Kuduva SS, McMahon JA, Moulton B, Walsh RDB, Rodríguez-Hornedo N, Zaworotko MJ. 2003. Crystal engineering of the composition of pharmaceutical phases: Multiplecomponent crystalline solids involving carbamazepine. Cryst Growth Des 3:909-919.
19. McNamara DP, Childs SL, Giordano J, Iarriccio A, Cassidy J, Shet MS, Mannion R, O'Donnell E, Park A. 2006. Use of a glutaric acid cocrystal to improve oral bioavailability of a low solubility API. Pharm Res 23:1888-1897.

20. Nehm S, Rodríguez-Spong B, Rodríguez-Hornedo N. 2006. Phase solubility diagrams of cocrystals are explained by solubility product and solution complexation. Cryst Growth Des 6:592-600.

21. Rodríguez-Hornedo N, Nehm SJ, Seefeldt KF, Pagán-Torres Y, Falkiewicz CJ. 2006. Reaction crystallization of pharmaceutical molecular complexes. Mol Pharm 3:362-367.

22. Henck JO, Bernstein J, Ellern A, Boese R. 2001. Disappearing and reappearing polymorphs. The benzocaine: Picric acid system. J Am Chem Soc 123:1834-1841.

23. Rodríguez-Hornedo N, Murphy D. 2004. Surfactant-facilitated crystallization of dihydrate carbamazepine during dissolution of anhydrous polymorph. J Pharm Sci 93:449-460.

24. Rodríguez-Spong B. 2005. Enhancing the pharmaceutical behavior of poorly soluble drugs through the formation of cocrystals and mesophases, Ph.D. Thesis, University of Michigan.

25. Rodríguez-Spong B, Zocharski P, Billups J, McMahon J, Zaworotko MJ, Rodríguez-Hornedo N. 2003. Enhancing the pharmaceutical behavior of carbamazepine through the formation of cocrystals. AAPS J 5:M1298.

26. Rodríguez-Hornedo N, Nehm SJ, Jayasankar A. 2007. Cocrystals: Design, properties, and formation mechanisms. Encyclopedia of pharmaceutical technology. 3rd edition. New York, NY: Francis \& Taylor Publishers. pp 615-635.

27. Remenar JF, Morissette SL, Peterson ML, Moulton B, MacPhee JM, Guzman HR, Almarsson O. 2003. Crystal engineering of novel cocrystals of a Triazole Drug with 1,4-Dicarboxylic acids. J Am Chem Soc 125:8456-8457.

28. Trask AV, Motherwell WDS, Jones W. 2005. Pharmaceutical cocrystallization: Engineering a remedy for caffeine hydration. Cryst Growth Des 5:1013-1021.

29. Childs SL, Chyall LJ, Dunlap JT, Smolenskaya VN, Stahly BC, Stahly GP. 2004. Crystal engineering approach to forming cocrystals of amine hydrochlorides with organic acids. Molecular complexes of fluoxetine hydrochloride with benzoic, succinic, and fumaric acids. J Am Chem Soc 126:1333513342.

30. Trask AV, Jones W. 2005. Crystal engineering of organic cocrystals by the solid-state grinding approach. Top Curr Chem 254:41-70.

31. Morissette SL, Almarsson O, Peterson ML, Remenar JF, Read MJ, Lemmo AV, Ellis S, Cima MJ, Gardner CR. 2004. High-throughput crystallization: Polymorphs, salts, co-crystals and solvates of 
pharmaceutical solids. Adv Drug Del Rev 56:275300 .

32. Pedireddi VR, Jones W, Chorlton AP, Docherty R. 1996. Creation of crystalline supramolecular arrays: A comparison of co-crystal formation from solution and by solid-state grinding. Chem Comm 987-988.

33. Shan N, Toda F, Jones W. 2002. Mechanochemistry and co-crystal formation: Effect of solvent on reaction kinetics. Chem Comm 2372-2373

34. Otsuka M, Matsumoto T, Kaneniwa N. 1986. Effect of environmental temperature on polymorphic solid-state transformation of indomethacin during grinding. Chem Pharm Bull 34:1784-1793.

35. Otsuka M, Ofusa T, Matsuda Y. 1999. Effect of environmental humidity on the transformation pathway of carbamazepine polymorphic modifications during grinding. Colloids Surf B Biointerfaces 13:263-273.

36. Crowley KJ, Zografi G. 2002. Cryogenic grinding of indomethacin polymorphs and solvates: Assessment of amorphous phase formation and amorphous phase physical stability. J Pharm Sci 91: 492-507.

37. Sheth AR, Lubach JW, Munson EJ, Muller FX, Grant DJW. 2005. Mechanochromism of piroxicam accompanied by intermolecular proton transfer probed by spectroscopic methods and solid-phase changes. J Am Chem Soc 127:6641-6651.

38. Oguchi T, Kazama K, Yonemochi E, Churimaworapan S, Choi W-S, Limmatvapirat S, Yamamoto K. 2000. Specific complexation of ursodeoxycholic acid with guest compounds induced by co-grinding. Phys Chem Chem Phys 2:2815-2820.

39. Jayasankar J, Somwangthanaroj A, Sirinutsomboon B, Shao ZJ, Rodríguez-Hornedo N. 2004. Cocrystal formation by solid-state grinding and during storage. AAPS J 6:R6159.

40. Jayasankar A, Somwangthanaroj A, Shao ZJ, Rodríguez-Hornedo N. 2006. Cocrystal formation during grinding and storage is mediated by amorphous phase. Pharm Res 23:2381-2392.

41. Jenkins MJ, Hay JN. 1999. Thermal analysis of crystalline polymer blends. J Therm Anal Calor 56: 1081-1086.

42. Rasband WS. 1997-2005. ImageJ, U.S. National Institutes of Health, Bethesda, Maryland, USA http://rsb.info.nih.gov/ij/.

43. Kissinger HE. 1957. Reaction kinetics in differential thermal analysis. Anal Chem 29:1702-1706.

44. Burger A, Ramberger R. 1979. Polymorphism of pharmaceuticals and other molecular-crystals. 1. Theory of Thermodynamic Rules. Mikrochim Acta 2:259-271. 